nocturnal neck pain and headache. Pittsburgh sleep quality index (PSQI) was used for sleep disturbance. Pre and post contrasts enhanced MRI interventions were done for both groups during the period of follow up (three months).

Results: Nocturnal neck pain, headache and sleep disturbance have significantly decreased, during follow up visits (3 months), in AAJ group in comparison to the control group. The Pre-intervention nocturnal pain score was $60.3 \pm 17.1$ in AAJ group \& $58.5 \pm 17.9$ in control group. Pain has significantly decreased after 2 weeks in AAJ group with continuous improvement till 3 months' post-intervention $6.9 \pm 4.65$ \& $51.26 \pm 10.54$ respectively. The pre-intervention headache was $22.68 \pm 16.74$ in AAJ group \& 45.17 \pm 15.83 in control group decreased to $7.54 \pm 5.23$ \& $48.52 \pm 11.98$ respectively post intervention. The percentage of patients who had sleep disturbance at baseline was $66.7 \%$ \& $73.3 \%$ in AAJ and control groups respectively which has significantly decreased to $6.7 \%$ \& $43.3 \%$ after 3 months. Regarding MRI, AAJ group had a statistical significant decrease in the percentage of patients with MRI synovial enhancement, inflammatory pannus, fibrosis and bone marrow edema in comparison to control group 3 months post intervention. All post-procedural side effects resolved within thmonth without further medical intervention, and no long-term sequelae were identified

Conclusion: Fluoroscopic guided intra-articular steroid injection of inflamed atlantoaxial joints is considered a beneficial therapeutic option in rheumatoid arthritis patients regarding clinical and radiological assessments.

References:

[1] Taniguchi D, Tokunaga D, Hase $\mathrm{H}$, et al. Evaluation of lateral instability of AAJ in RA using dynamic open-mouth view radiographs. Clin Rheumatol. 2008 Jul. 27(7):851-7.

Disclosure of Interests: None declared

DOI: 10.1136/annrheumdis-2020-eular.1810

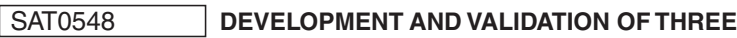 PRELIMINARY MRI SACROILIAC JOINT COMPOSITE STRUCTURAL DAMAGE SCORES IN A 5-YEAR LONGITUDINAL STUDY OF PATIENTS WITH AXIAL SPONDYLOARTHRITIS}

M. Wetterslev ${ }^{1}$, M. Ǿstergaard ${ }^{1}$, I. J. Sørensen ${ }^{1}$, U. Weber ${ }^{2}$, A. G. Loft ${ }^{3,4}$ G. Kollerup ${ }^{1}$, L. Juul ${ }^{1}$, G. Thamsborg ${ }^{1}$, O. Madsen ${ }^{1}$, J. Møllenbach Møller ${ }^{5}$, S. Juhl Pedersen ${ }^{1}{ }^{1}$ Rigshospitalet, Copenhagen Center for Arthritis Research, Center for Rheumatology and Spine Diseases, Copenhagen, Denmark; ${ }^{2}$ Danish Hospital for Rheumatic Diseases, University Hospital of Southern Denmark, Soenderborg, Denmark; ${ }^{3}$ Hospital Lillebælt, Department of Rheumatology, Vejle, Denmark; ${ }^{4}$ Aarhus University Hospital, Department of Rheumatology, Aarhus, Denmark; ${ }^{5}$ Herlev Hospital, Department of Radiology, Copenhagen, Denmark

Background: In axial spondyloarthritis (axSpA), MRI reliably detects structural lesions in the sacroiliac joints (SIJs). The SPARCC SIJ Structural Score (SSS) (1) is a reliable and validated method to assess the individual structural lesions of the SIJs, i.e. fat lesion, erosion, backfill (fat metaplasia in an erosion cavity) and ankylosis. Several MRI studies have indicated that bone destruction, i.e. erosion, is often followed by formation of new bone in the erosion cavity (backfill), ultimately leading to ankylosis(2).

Objectives: The aim was to combine SPARCC SSS for erosion, backfill and ankylosis into a composite score for SIJ structural damage and to test this score in a 5-year follow up study.

Methods: Thirty-three patients fulfilling ASAS criteria for axSpA were followed for 5 years after initiation of TNF inhibitor in the BIOSPA study(3). T1-weighted and STIR MRI sequences of the SIJs acquired at week 0,46 and year 2, 3, 4, 5 were evaluated with SPARCC SSS. In each of 5 slices of each SIJ, erosion is scored 0-1 per joint quadrant (score range 0-40), backfill 0-1 per joint half (score range 0-20) and ankylosis 0-1 per joint half (score range 0-20). Based on the scores for erosion, backfill and ankylosis 3 versions of a preliminary Composite axSpA MRI SIJ Structural Damage Score (CSDS) were calculated:

CSDS-A: (erosion score $\mathrm{x} 0.5)+$ backfill score + ankylosis score

CSDS-B: (erosion score $\mathrm{x} 1)+($ backfill score $\times 4)+($ ankylosis score $\times 6)$

CSDS-C: (erosion score $\mathrm{x} 1)<$ (backfill score $\mathrm{x} 4$ ) < (ankylosis score $\mathrm{x} 6$ )

The "<" indicates a hierarchical order, meaning that erosion was not scored if backfill was present in the same joint half and erosion and backfill were not scored if ankylosis was present in the joint half.

Results: Patients were divided into two groups: patients with almost complete bilateral ankylosis (baseline SPARCC SSS Ankylosis $\geq 18, n=10$ ) and patients with no/minor ankylosis (baseline SPARCC SSS Ankylosis $\leq 7, n=23$ ). At baseline patients with no/minor ankylosis were younger, had shorter symptom duration, lower BASMI, higher SPARCC SIJ Inflammation, lower SSS Fat, Erosion, Backfill and Ankylosis, as compared with patients with almost complete ankylosis.

At baseline, CSDS-A, -B and -C correlated positively with SPARCC SSS Fat and Ankylosis and modified New York criteria grading, and negatively with BASDAI and SPARCC inflammation. Change in CSDS-B and -C over 5 years correlated positively with change in SSS Fat and Ankylosis and negatively with change in SPARCC Inflammation. There was no change in the group with almost complete ankylosis.
The annual progression for CSDS-B and - $C$ was statistically significantly larger in year 1 compared with year $4(p=0.01)$ and numerically larger compared with year $2(p=0.075), 3(p=0.382)$ and $5(p=0.073)$. Figure 1 shows the annual change in patients with no/minor ankylosis.

Figure 1 Composite Structural Damage Score-A

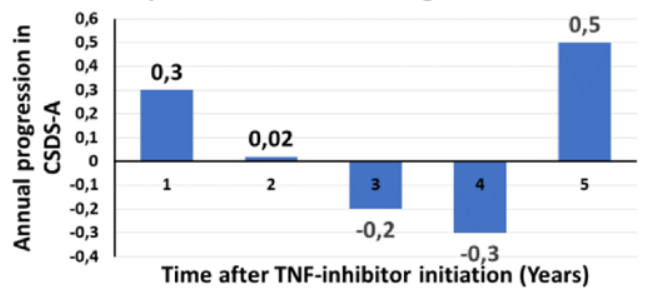

Composite Structural Damage Score-B

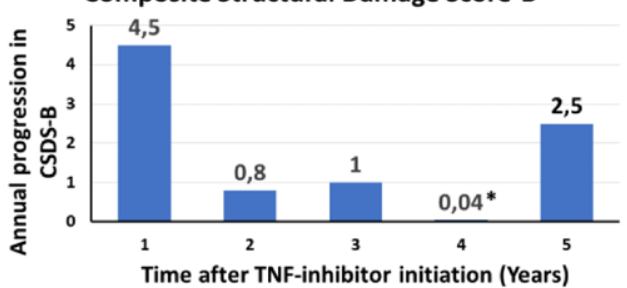

Composite Structural Damage Score-C

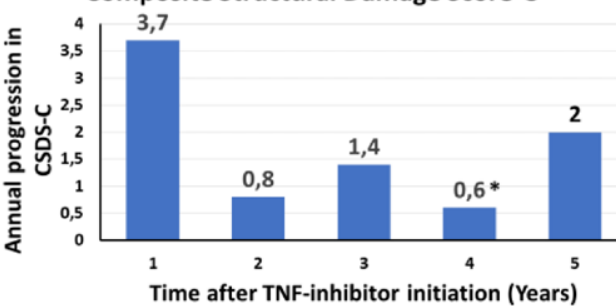

Figure 1. The figure shows the annual progression in the group with no/minor ankylosis at baseline in CSDS -A, -B and -C. Data are shown as mean. Annual progression was calculated as the change between MRI scans divided by the exact interval (years) between MRI assessments. Comparison of annual progression year 1 (week 0-46) with the other time intervals were calculated with Wilcoxon signed rank test. ${ }^{*} \mathrm{p}<0.05$.

Conclusion: Three preliminary Composite Structural Damage Scores for MR assessment of the SIJs in patients with axSpA, which allows scoring of MR progression of erosion through backfill to ankylosis, were introduced. Progression was most pronounced the first year after TNF inhibitor initiation. This novel approach may be useful for monitoring structural progression in axSpA. We suggest that these methods are further tested for responsiveness and ability to differentiate between different therapies in randomized controlled trials.

References:

[1] Maksymowych WP et al. J Rheum 2015;42:79-86.

[2] Maksymowych WP et al. Art Rheum 2014;66:2958-67.

[3] Pedersen SJ et al. Scand J Rheum 2019;48:185-197.

Disclosure of Interests: Marie Wetterslev: None declared, Mikkel Ǿstergaard Grant/research support from: AbbVie, Bristol-Myers Squibb, Celgene, Merck, and Novartis, Consultant of: AbbVie, Bristol-Myers Squibb, Boehringer Ingelheim, Celgene, Eli Lilly, Hospira, Janssen, Merck, Novartis, Novo Nordisk, Orion, Pfizer, Regeneron, Roche, Sandoz, Sanofi, and UCB, Speakers bureau: AbbVie, Bristol-Myers Squibb, Boehringer Ingelheim, Celgene, Eli Lilly, Hospira, Jans sen, Merck, Novartis, Novo Nordisk, Orion, Pfizer, Regeneron, Roche, Sandoz, Sanofi, and UCB, Inge Juul Sørensen: None declared, Ulrich Weber: None declared, Anne Gitte Loft Grant/research support from: Novartis, Consultant of: AbbVie, MSD, Novartis, Pfizer and UCB, Speakers bureau: AbbVie, MSD, Novar tis, Pfizer and UCB, Gina Kollerup Speakers bureau: Eli Lilly, Lars Juul: None declared, Gorm Thamsborg: None declared, Ole Madsen: None declared, Jakob Møllenbach Møller: None declared, Susanne Juhl Pedersen Grant/research support from: Novartis

DOI: 10.1136/annrheumdis-2020-eular.2683

\section{SAT0549 $\quad$ A SEMI-QUANTITATIVE MRI SCORING SYSTEM FOR INFLAMMATION IN JOINTS AND ENTHESES IN THE LOWER EXTREMITIES DEMONSTRATES GOOD RELIABILITY AND VALIDITY: POST-HOC ANALYSIS OF DATA FROM THE CRESPA TRIAL}

S. Krabbe ${ }^{1,2}$, T. Renson ${ }^{3,4}$, L. Jans ${ }^{5}$, D. Elewaut ${ }^{3,4}$, F. Van den Bosch ${ }^{3,4}$,

P. Carron ${ }^{3,4}$, M. Ǿstergaard ${ }^{1,2} .{ }^{1}$ Rigshospitalet, Copenhagen Center for Arthritis Research, Center for Rheumatology and Spine Diseases, Glostrup, Denmark; 
${ }^{2}$ University of Copenhagen, Department of Clinical Medicine, Faculty of Health and Medical Sciences, Copenhagen, Denmark; ${ }^{3}$ Ghent University Hospital, Department of Rheumatology, Ghent, Belgium; ${ }^{4}$ Ghent University, VIB Inflammation Research Center, Ghent, Belgium; ${ }^{5}$ Ghent University Hospital, Department of Radiology, Ghent, Belgium

Background: MRI allows an objective assessment of signs of inflammation in peripheral joints and entheses and is therefore of potential interest as outcome measure in trials. No knowledge exists on the reliability and validity of semi-quantitative MRI scores in the setting of peripheral spondyloarthritis (pSpA). Objectives: To describe the reliability of a semi-quantitative lower-extremity MRI scoring system, to investigate correlation with known measures of disease activity and ability to capture patients with improvement during treatment.
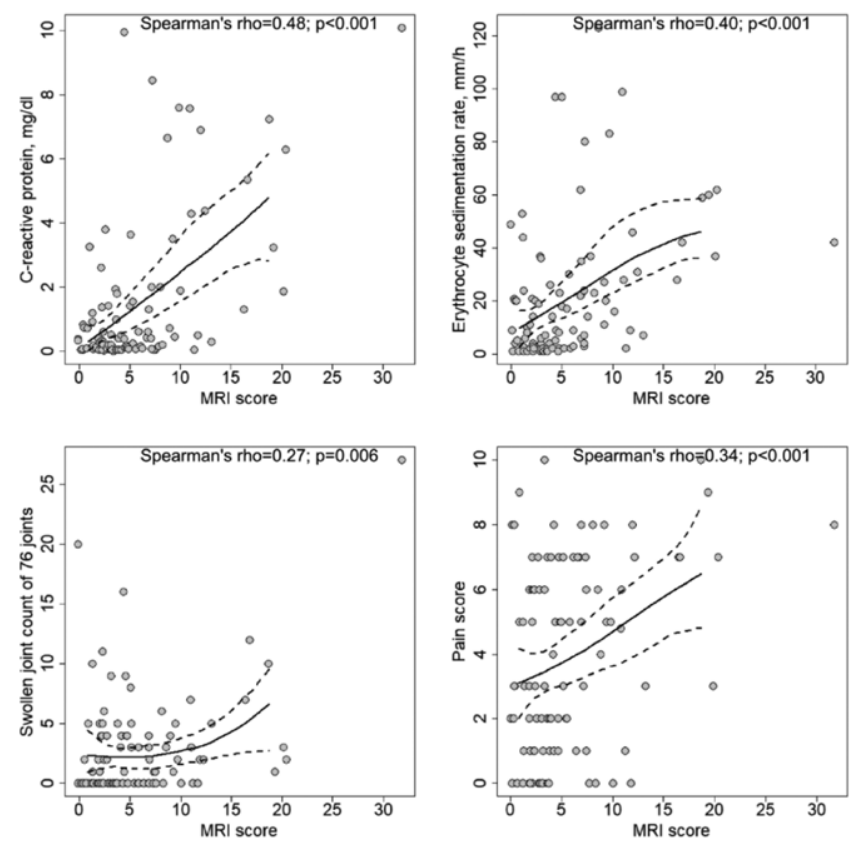

Figure 1. Validity demonstrated by positive relations between MRI score and established measures of disease activity, using data from both timepoints. Scatter plots, loess curves with bootstrap $95 \%$ confidence intervals and Spearman's rho with p-values.

Methods: In a post-hoc analysis, scores from 3 readers (LJ, MØ, SK) who independently assessed MRI images of pelvis (except sacroiliac joints), knees and ankles in the CRESPA trial blinded to chronology and all clinical data, were further analyzed. Entheses were scored 0-3 (none/mild/moderate/severe) for soft tissue inflammation (19 sites) and 0-3 for bone marrow edema (24 sites), joints were scored 0-3 for effusion/synovitis (10 sites) and 0-3 for bone marrow edema (22 sites). MRI score was defined as the sum of scores from all joints and entheses (i.e. all 75 sites). The CRESPA trial (NCT01426815) included 60 patients with early pSpA, defined as a symptom duration of $<12$ weeks. All patients fulfilled the Assessment of SpondyloArthritis international Society criteria for $\mathrm{pSpA}$; data from 56 patients with available MRI images at baseline were included in this analysis, 46 had available MRI images at follow-up. Follow-up MRI was only performed if sustained clinical remission was reached. Reliability was assessed using two-way intra-class correlation coefficient (ICC) models by absolute agreement, single-measure (relevant when using scores from 1 reader) and average-measure (relevant when using averaged scores from 3 readers).

Results: MRI scores at baseline were mean 7.2 (median 5, inter-quartile range 3 to 9 , range 0 to 32). MRI change scores were mean -3.1 and (median -1 , IQR -4 to 0 , range -18 to 2$)$. MRI status scores at baseline $(n=56)$ had single measure ICC 0.78 (95\% Cl: 0.66-0.87) and average measure ICC 0.92 (0.85-0.95). MRI change scores $(n=46)$ had single measure ICC $0.73(0.57-0.84)$ average measure ICC 0.89 (0.80-0.94).

MRI status scores correlated significantly with CRP, ESR, swollen joint count and pain score.

Patients with PSpARC40 response $(n=34)(\geq 40 \%$ improvement in disease activity according to the Peripheral SpA Response Criteria) had larger decreases in MRI scores compared to patients without PSpARC40 response $(n=11)$, mean -3.4 vs. $-1.0, p=0.03$.

When using all MRI data from pelvis, knees and ankles combined, more patients could be identified to have improvement, as compared to only taking one of three parts into account.

\begin{tabular}{lcccc}
\hline & $\begin{array}{c}\text { MRI scores } \\
\text { of pelvis, } \\
\text { knees and feet } \\
\text { combined }\end{array}$ & $\begin{array}{c}\text { MRI scores of } \\
\text { pelvis only }\end{array}$ & $\begin{array}{c}\text { MRI scores of } \\
\text { knees only }\end{array}$ & $\begin{array}{c}\text { MRI } \\
\text { scores } \\
\text { of ankles } \\
\text { only }\end{array}$ \\
\hline $\begin{array}{l}\text { Number of patients with improve- } \\
\text { ment in MRI score }>\text { SDC }\end{array}$ & $15(33 \%)$ & $9(20 \%)$ & $12(26 \%)$ & $14(30 \%)$ \\
$\begin{array}{l}\text { Number of patients with improve- } \\
\text { ment in MRI score } \geq 50 \%\end{array}$ & $21(46 \%)$ & $10(22 \%)$ & $20(43 \%)$ & $17(37 \%)$ \\
$\begin{array}{l}\text { Net number of patients with } \\
\text { improvement in MRI score* }\end{array}$ & $24(52 \%)$ & $6(13 \%)$ & $21(46 \%)$ & $15(33 \%)$ \\
$\begin{array}{l}\text { Number of patients with improve- } \\
\text { ment in MRI score as assessed by }\end{array}$ & $17(37 \%)$ & $3(7 \%)$ & $11(24 \%)$ & $13(28 \%)$ \\
3 readers & & & & \\
\hline
\end{tabular}

${ }^{*}$ Patients with improvement minus patients with worsening.

Conclusion: The semi-quantitative lower-extremity MRI score showed acceptable reliability and validity. The ability to capture response was best when combining information from all available areas that were imaged, i.e. both pelvis, knees and ankles.

*First authorship is shared between SK and TR.

Disclosure of Interests: Simon Krabbe Grant/research support from: AbbVie, MSD, Novartis, Thomas Renson: None declared, Lennart Jans: None declared Dirk Elewaut: None declared, Filip van den Bosch Consultant of: AbbVie, Celgene Corporation, Eli Lilly, Galapagos, Janssen, Novartis, Pfizer, and UCB, Speakers bureau: AbbVie, Celgene Corporation, Eli Lilly, Galapagos, Janssen, Novartis, Pfizer, and UCB, Philippe Carron: None declared, Mikkel Ǿstergaard Grant/ research support from: AbbVie, Bristol-Myers Squibb, Celgene, Merck, and Novartis, Consultant of: AbbVie, Bristol-Myers Squibb, Boehringer Ingelheim, Celgene, Eli Lilly, Hospira, Janssen, Merck, Novartis, Novo Nordisk, Orion, Pfizer, Regeneron, Roche, Sandoz, Sanofi, and UCB, Speakers bureau: AbbVie, Bristol-Myers Squibb, Boehringer Ingelheim, Celgene, Eli Lilly, Hospira, Janssen, Merck, Novartis, Novo Nordisk, Orion, Pfizer, Regeneron, Roche, Sandoz, Sanofi, and UCB DOI: 10.1136/annrheumdis-2020-eular.4108

\section{SAT0550 SPINAL AND PELVIC MDCT USING “IDOSE5" ITERATIVE RECONSTRUCTION ALGORITHM IN PATIENTS WITH PSORIATIC SPONDYLOARTHRITIS: DIAGNOSTIC CAPABILITIES AND IMAGE QUALITY IN RELATION TO RADIATION EXPOSURE}

V. Bizimi ${ }^{1}$, P. Katsimbri ${ }^{2}$, A. Plousi ${ }^{3}$, D. Tseronis ${ }^{2}$, N. Sideri ${ }^{1}$, E. Efstathopoulos ${ }^{3}$, D. Boumbas ${ }^{2}$, N. Kelekis ${ }^{1}$, O. Papakonstantinou ${ }^{1} .{ }^{1}$ Attikon University Hospital of Athens, 2nd Radiology Dpt, Athens, Greece ${ }^{2}$ Attikon University Hospital of Athens, Rheumatology \&Clinical Immunology Unit, 4th Department of Internal Medicine, Athens, Greece; ${ }^{3}$ Attikon University Hospital of Athens, Department of Medical Physics, Athens, Greece

Background: Psoriatic spondyloarthritis (PsSpA) is an inflammatory arthritis related to psoriasis, whereas a large number of patients may have persistent inflammation developing gradual and in some cases extensive joint involvement of the axial skeleton.

Conventional radiographs (CRs) have been used for the detection of structural damage (syndesmophyte formation, paravertebral ossification, sacroilitis, ankyloses and erosions), facilitating as an important measure of efficacy of various therapies. However overlapping of anatomic structures of pelvis and spine as well as limited capabilities to visualize soft tissue have led to the development of newer imaging technologies (1). Multidetector CT technology (MDCT), it is now possible to perform low dose CT (IdCT) of the entire vertebral column, viewed in multiple planes and without overprojection with a low radiation dose. (2) Still, the capabilities of IdCT algorithms in the diagnosis and progression of PsSpA has not been fully explored.

Objectives: The aim of this study is to examine the effect of "iDose5" iterative reconstruction algorithm on radiation dose, diagnostic capabilities and image quality in spine-pelvis (S-P) CT scanning compared with CRs, in detection of findings suggestive of PsSpA.

Methods: Thirty-nine patients with PsSpA (26 females and 13 males, age range: 23 to 70 years old) were prospectively studied with "iDose5" CT of spine and pelvis on a 64-row MDCT scanner. Multiplannar reformats followed. All patients satisfied the Psoriatic Arthritis (CASPAR) classification criteria and had undergone standard AP and lateral $C R$ s of the cervical, thoracic and lumbar spine and AP radiographs of the pelvis within one months of the iDose $\mathrm{CT}$. Twenty-five patients underwent, additional MR imaging (MRI) of the same anatomic areas. Written consent was obtained from all patients. Two musculoskeletal radiologists read and scored CT scans and CRs in consensus, according to the PASRI criteria and the CTSS score. CT image quality and effective dose for CT and radiographs were assessed.

All data were analyzed using SPSS 24.0 statistical software. 